правоведами). Лишь совместные усилия обучающих и обучаемых могут дать желаемый результат.

$$
* * *
$$

1. Бевзер Р. Об особенностях русского письменного юридического языка // Почему мы так плохо пишем юридические тексты [Электронный ресурс]. Режим доступа: HTTPS://ZAKON.RU/BLOG/2021/01/26/OB OSOBENNOSTYAH_RUSSKOGO_PISMENNOGO_YURIDICHESKOGO_YAZYKA_POCHEMU_MY_TA K_PLOHO_PISHEM_YURIDICHESKI

2. Воскобитова Л.А. и др. Профессиональные навыки юриста: Опыт практического обучения. М.: Дело, 2001. $416 \mathrm{c}$.

3. Доброхотова Е.Н. Профессиональные навыки юриста: Учебник. М., 2018. [Электронный ресурс]. Режим доступа: https://studme.org/286050/pravo/tipichnye_oshibki_yuridicheskih_dokumentah\#619

4. Долгодворова А.А. Частотные ошибки, встречающиеся в судебных актах. Практическая стилистика. Пособие по русскому языку. Екатеринбург: Федеральный арбитражный суд Уральского округа, 2011. 40 с.

5. Ивакина Н.Н. Профессиональная речь юриста: Учебное пособие. М.: Норма, 2008. 448 c.

6. Кожевников В.В., Сенин И.Н., Красман А.И. Технологии создания правовых документов в процессе осуществления юридической деятельности: Монография. Омск: Издательство АНО ВО «Омский экономический институт», 2016. 174 с. [Электронный ресурс]. Режим доступа: https://lawbook.online/tehnikiyuridicheskoy-osnovyi/tehnologii-sozdaniya-pravovyih-dokumentov.html

7. Краснов Ю.К., Надвикова В.В., Шкатулла В.И. Юридическая техника: Учебник. М.: Юстицинформ, 2014. $536 \mathrm{c.}$

8. Кудрявцева Е.В., Прокудина Л.А. Как написать судебное решение. М.: Издательство Юрайт, 2017. [Электронный ресурс]. Режим доступа: https://mydocx.ru/10-135562.html

9. Шувалова Н.Н., Иванова А.Ю. Основы делопроизводства. Язык служебного документа: учебник и практикум для академического бакалавриата. М.: Издательство Юрайт, 2019. 428 с.

\title{
Блинова А.А. \\ Фразеологизмы семантического поля «состояние» в русском и чешском языках: понятие относительной эквивалентности
}

ФГАОУ «Волгоградский государственный университет»

(Россия, Волгоград)

doi: 10.18411/trnio-10-2021-131

\section{Аннотация}

В настоящей работе рассмотрены фразеологические единицы русского и чешского языков с точки зрения их эквивалентности. Определена специфика полностью эквивалентных фразеологизмов, а также выявлены признаки, отличающие абсолютно эквивалентные фразеологические единицы от относительно эквивалентных, названы критерии определения относительного эквивалента. Приведены примеры полностью и относительно эквивалентных фразеологизмов в русском и чешском языках, описана их грамматическая структура, обозначено лексическое значение и степень экспрессии. Сделаны выводы по поводу частотности явления относительной эквивалентности в русско-чешской фразеологии.

Ключевые слова: фразеологизм, эквивалент, лексическое значение, русский язык, чешский язык.

\section{Abstract}

In this study, the phraseological units of the Russian and Czech languages are considered from the point of view of their equivalence. The specificity of full equivalent phraseological units is determined, as well as the signs that distinguish full equivalent phraseological units from relative equivalent phraseological units are identified, the criteria for determining the relative equivalent are named. Examples of complete and relative equivalent phraseological units in the Russian and Czech languages are given, their grammatical structure is described, the lexical meaning and the degree of expression are indicated. Conclusions are drawn about the frequency of the phenomenon of relative equivalence in Russian-Czech phraseology.

Keywords: phraseology, equivalent, lexical meaning, Russian language, Czech language. 
Полностью эквивалентные фразеологизмы представляют собой такие единицы, которые совпадают по значению, образности, стилистической направленности, лексическому составу и грамматической структуре. В исследовании мы опираемся на классификацию эквивалентности А.В. Кунина, которая нами была несколько расширена, вследствие чего были разграничены понятия абсолютной эквивалентности и относительной эквивалентности фразеологических единиц (ФЕ).

Относительный фразеологический эквивалент имеет следующие показатели, не присущие абсолютному эквиваленту:

\section{- отличные, иные, часто синонимические компоненты;}

- наличие изменений в форме ФЕ;

- возможное изменение синтаксического построения и др [4, с. 7-9].

В остальном такой фразеологизм может являться полноценным соответствием переводимой на данный язык ФЕ. Различия могут наблюдаться не только в компонентах, синтаксисе и сочетаемости, но в разной семантической наполняемости. Так, фразеологизм русского языка говорить от сердияа [3, с. 154] имеет семантическое значение «говорить искренне, откровенно», но чешский фразеологизм promluvit ze srdce [5, с. 311] имеет иное семантическое наполнение - «Говорить о чём-то тайном и сокровенном». Данные ФЕ можно считать полными эквивалентами, если в качестве критериев полной эквивалентности рассматривать только компоненты ФЕ, их форму и синтаксис. Но если брать во внимание различия в семантическом значении, данные фразеологизмы можно назвать относительно эквивалентными.

Как мы уже заметили выше, фразеологизмы могут иметь явные отличия в компонентном составе, но иметь полную эквивалентность в лексическом значении. Такие фразеологизмы мы также будем причислять к группе относительно эквивалентных. Например, в составе русских и чешских фразеологизмов мы можем наблюдать выражение одного и того же образа с помощью разных лексических единиц, которые могут либо сужать экспрессивность фразеологизма, либо расширять её. Например, в составе русского фразеологизма спит как убитый лексическая единица убитый и так является экспрессивно окрашенной, имеет негативное наполнение, но чешский фразеологизм spí jako zabitý, с абсолютно таким же лексическим значением, является более экспрессивно маркированным, так как лексема забитый подразумевает значение «убитый с жестокостью, забитый чем-то (палками, камнями) до смерти».

Анализ фразеологизма требует достаточного внимания к каждому из его компонентов, при таком анализе необходимо учитывать не только лексическое наполнение $Ф Е$, но и его морфологическое и синтаксическое оформление. Существенный вклад в теорию перевода фразеологизмов вложил отечественный учёный В.С. Виноградов, который считал, что при переводе ФЕ особую роль играют смысл, эмоции, функция, стиль. Учёный считает, что «в переводе необходимо сохранить смысловое, эмоционально-экспрессивное и функционально-стилистическое содержание, которое передавалось соответствующим устойчивым словосочетанием в контексте оригинала [1, с. 180].

Большинство фразеологических единиц, рассматриваемых нами в рамках данной работы, обнаруживают близость семантики в русском и чешском языках, то есть являются полностью совпадающими в их лексическом значении. Случаи несовпадения внешнего вида фразеологизма или случаи дополнительного экспрессивного оттенка в семантике фразеологической единицы будут нами прокомментированы.

Рассмотрим русский фразеологизм Называть вещи своими именами (значение: говорить прямо, откровенно, не употребляя смягчающих слов, выражений) и чешский фразеологизм Nazývat věci svými jmény (значение то же, что и у русского фразеологизма говорить прямо) - здесь мы наблюдаем полное совпадение и в лексическом, и в морфологическом составе фразеологизмов, следовательно, перед нами явление полной эквивалентности. Русский фразеологизм Сказать как есть (значение: сказать честно, без 
утаивания чего-либо) отличается лаконичностью и нейтральностью, не отражает в своей семантике экспрессивного оттенка. $\quad$ Чешский фразеологизм Říkat na plnou pusu - букв. «говорить на полный рот» (значение полностью совпадает со значением русского фразеологизма - говорить честно), но данная ФЕ отражает понятие относительной эквивалентности, т.е., полностью совпадая в плане содержания, фразеологизм имеет отличающийся от русской ФЕ план выражения (чеш. К̌́ikat na plnou pusu- русск. Говорить на полный рот), что в данном случае влияет на степень экспрессии, увеличивая эмоциональную нагрузку фразеологизма. Эффект экспрессии создаётся с помощью лексем «полный» и «рот», которые являются нейтральными словами, однако в совокупности выражают значение: «сказать всё и даже то, чего не стоило говорить» [5, с. 298].

Русский фразеологизм Быть на коне (значение: кто-либо оказался в выгодном, выигрышном положении, в положении победителя) - фразеологизм экспрессивен, образен, выражает положительную оценку ситуации. Чешский фразеологизм Být na koni (значение совпадает со значением русского аналога -оказаться в выгодном положении) - фразеологизм чешского языка полностью совпадает и в плане выражения, и в плане содержания с русским фразеологизмом. ФЕ экспрессивна, лаконична, строится по классической схеме: «инфинитив + предлог + образ», выражает положительную оценку ситуации.

Приведенные выше фразеологические единицы русского и чешского языков выражают положительную или нейтральную эмоциональную оценку, являются экспрессивными, нормативными, частотными и общеупотребительными. ФЕ Быть на коне (чеш. Být na koni) строится по типичной схеме с глаголом в форме инфинитива + предлог + образ (в данном случае животного), что упрощает понимание его семантики (человек, сидящий на коне находится в более выгодном положении, чем человек, стоящий на ногах и в плане скорости, и в плане возможностей). Нами был сделан вывод, что в русском и чешском языках представлена небольшая группа полностью эквивалентных фразеологизмов с нейтральной или положительной окраской, самые частотные из которых были рассмотрены выше.

Фактический материал исследования показал, что полностью эквивалентных или относительно эквивалентных фразеологизмов с негативной окраской и в русском и в чешском языке представлено больше, чем нейтрально или положительно окрашенных. Однако среди ФЕ, имеющих в лексическом значении негативный оттенок, большее количество всё-таки можно назвать относительно эквивалентными, чем полностью эквивалентными.

Русский фразеологизм Биться как рыба об лед (значение: сильно нуждаясь, бесплодно, безрезультатно добиваться улучшения материального положения) имеет экспрессивную окраску, частотен, общеупотребителен, нормативен. Чешский фразеологизм Házet sebou jako kapr na suchu - русск. Бросаться как карп на сушу (значение фразеологизма совпадает по лексическому значению, но в семантике ФЕ отсутствует компонент «материальное положение», то есть чешский фразеологизм имеет следующее значение: упорно, но безрезультатно добиваться чего-либо). В данном случае наблюдается явление относительной эквивалентности, так как у фразеологизмов русского и чешского языков очень схожи и план выражения, и план содержания, что не позволяет отнести ФЕ в группу частично эквивалентных.

Далее рассмотрим явление относительной эквивалентности с точки зрения морфологического состава: русский фразеологизм Валять дурака (значение: дурачиться, поясничать, потешать глупыми выходками) и чешский фразеологизм Dělat ze sebe blbce русск. Делать из себя дурака (значение ФЕ чешского языка полностью совпадает со значением ФЕ русского языка). Различия наблюдаются только в грамматическом построении фразеологизма - переходный глагол + предлог + субъект + сущ. в Вин. П. (в русском языке схема построения иная: переходный глагол сочетается с существительным без предлога). 
В целом явление относительной эквивалентности применительно к фразеологизмам в русском и чешском языках встречается не так часто. Однако нами обнаружены частные случаи, которые мы рассмотрели в данной работе.

Такое редкое несовпадение формы и содержания мы объясняем всё-таки родственностью языков, их славянским происхождением. Но не стоит забывать о принципиальном отличии русского и чешского менталитета, что, конечно же, находит отражение во фразеологизмах с частичной эквивалентностью.

$$
* * *
$$

1. Виноградов, В. С. Введение в переводоведение (общие и лексические вопросы) / В. С. Виноградов. - М. : Издательство института общего среднего образования РАО, 2001. - 181 с.

2. Королевская, Е. М. Фразеологическая репрезентация предикатной характеристики обобщенного субъекта в русском, чешском и английском языках : дисс. ... канд. филол. наук / Королевская Екатерина Михайловна. Волгоград, 2012.

3. Кохтев, Н. Н. Русская фразеология / Н. Н. Кохтев, Д. Э. Розенталь. - М. : Русский Язык, 1990. - 306 с.

4. Кунин, А. В. Курс фразеологии современного английского языка / А. В. Кунин. - М. : Высш. Шк., 1986. $396 \mathrm{c}$.

5. Mokienko, V. Česko-ruský frazeologický slovník / V. Mokienko, A. Wurm. - Olomouc: Univ. Palackého v Olomouci, 2002. $-659 \mathrm{c}$.

\section{Бодулева А.Р., Нуримхаметова Л.К. \\ Неологизмы в период пандемии коронавируса (на материале англоязычного чата Twitter)}

Башкирский государственный университет

doi: $10.18411 /$ trnio-10-2021-132

(Россия, Уфа)

\section{Аннотация}

Цель исследования - выявить особенности словообразования новой лексики, которая отражает трансформации в английском языке в условиях пандемии. Научная новизна заключается в выявлении новых лексических единиц, появившихся в английском языке в условиях пандемии, и в описании специфики их образования. Полученные результаты показали, что большая часть новообразований представлена существительными, образованными путем словосложения и словослияния.

Ключевые слова: неологизм, словосложение, словослияние, коронавирус.

\section{Abstract}

The aim of the study is to identify the word formation features of the new vocabulary that reflects transformations in the English language in pandemic times. Scientific novelty lies in the identification of new lexical units that were coined in English in times of the pandemic and in the description of their formation specifics. The attained results showed that most of the neologisms are nouns formed by word composition and blending.

Keywords: neologism, word composition, blending, coronavirus.

Существует множество видов коммуникации, и один из них - интернеткоммуникация. Интернет-коммуникация означает общение, при котором коммуниканты не видят друг друга, посылают письменные формы сообщений, получают взаимный обмен и право доступа к информации, имеющейся в компьютерах участников коммуникации, возможна незамедлительная обратная связь через компьютер между двумя или более людьми. Виртуальное общение имеет ряд характеристик, присущих другим типам общения. По области охвата компьютерная коммуникация имеет характеристики массовой (общение с людьми со всего мира), внутриличностной (общение между пользователем и компьютером) и групповой коммуникации. Принимая во внимание временной фактор, компьютерное 